\title{
Does Disability Correlate With Impairment After Hand Injury?
}

\author{
Maryam Farzad PhD, Ali Asgari PhD, Fatemeh Dashab MSc, \\ Fereydoun Layeghi MD, Masoud Karimlou PhD, Seyed Ali Hosseini PhD, \\ Mehdi Rassafiani PhD
}

Published online: 5 March 2015

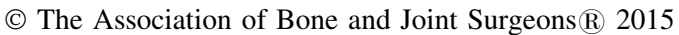

\begin{abstract}
Background Any loss or deviation in body function and structure is considered impairment, whereas limitations on activities are fundamental to the definition of disability. Although it seems intuitive that the two should be closely related, this might not be the case; there is some evidence that psychosocial factors are more important determinants of disability than are objective impairments. However, the degree to which this is the case has been incompletely explored.
\end{abstract}

Each author certifies that he or she, or a member of his or her immediate family, has no funding or commercial associations (eg, consultancies, stock ownership, equity interest, patent/licensing arrangements, etc) that might pose a conflict of interest in connection with the submitted article.

All ICMJE Conflict of Interest Forms for authors and Clinical

Orthopaedics and Related Research ${ }^{\circledR}$ editors and board members are on file with the publication and can be viewed on request.

Each author certifies that his or her institution approved the human protocol for this investigation, that all investigations were conducted in conformity with ethical principles of research, and that informed consent for participation in the study was obtained.

This work was performed at The University of Social Welfare and Rehabilitation Sciences, Tehran, Iran.

M. Farzad, F. Dashab, S. A. Hosseini, M. Rassafiani Department of Occupational Therapy, The University of Social Welfare and Rehabilitation Sciences, Tehran, Iran

\section{A. Asgari}

Department of Educational Psychology, The University of

Kharazmi, Tehran, Iran

F. Layeghi $(\bowtie)$

Department of Basic Science, The University of Social Welfare and Rehabilitation Sciences, Kodakyar Street, Daneshjo

Boulevard, Evin, 1985713831 Tehran, Iran

e-mail: Drlayeghi@yahoo.com
Questions/purposes The purpose of this study was to determine if disability (as measured by the Disabilities of the Arm, Shoulder and Hand [DASH] and the Michigan Hand Questionnaire [MHQ]) and pain intensity correlate with impairment (as measured by the American Medical Association [AMA] impairment guide). Secondary study questions addressed the effect of pain intensity and symptom of depression on predicting disability.

Methods Impairment and disability were evaluated in a sample of 107 hand-injured patients a mean of 11 months after injury. Impairment rating was performed prospectively. From the patients who came for therapy, they were invited to fill out the questionnaire and evaluated for impairment rating. Response variables of DASH, MHQ, and visual analog scale pain intensity values were collected at the same setting. Other explanatory variables included demographic, injury-related, and psychological factors (symptoms of depression measured with the Beck Depression Inventory). Initial bivariate and multivariate analyses were performed to determine correlations of disability and pain to impairment rating and other exploratory variables.

\section{Karimlou}

Social Determinant of Health Research Center and Biostatistics, The University of Social Welfare and Rehabilitation Sciences, Tehran, Iran 
Results Disability as measured by the DASH showed intermediate correlation with AMA impairment $(r=0.38$, beta $=0.36, \mathrm{p}=0.000)$. Together with gender, it accounted for only $22 \%$ of the variability in DASH scores. Similarly, MHQ score correlated with impairment rating $(\mathrm{r}=-0.24$, beta $=-0.23, \mathrm{p}<0.05)$. However, together with age, injured hand accounted for only $19 \%$ of the variability in MHQ scores. However, pain intensity did not correlate with impairment $(\mathrm{r}=-0.46, \mathrm{p}>0.05)$. Interestingly, pain intensity did correlate with the time passed from surgery but it was correlated with symptom of depression $\left(\mathrm{r}^{2}=0.10\right.$, beta $\left.=0.33, \mathrm{p}=0.001\right)$.

Conclusions The limited correlation between impairment and disability emphasizes the importance of factors other than pathophysiology in human illness behavior. These may include physical (pain, dominant injured hand) and conditional factors (time since surgery) or psychological factors such as depression and adapting; all mentioned can be considered as personal factors that may be different in each patient. So considering personal difference and any other condition except the impairment alone can help to better plan interventions and also diminish disability level. Level of Evidence Level III, therapeutic study.

\section{Introduction}

Hand and upper extremity impairment resulting from injury can hinder participation in social, family, and vocational activities. In other words, impairment can create disability. Any loss or deviation in body function and structure is considered impairment. Activity limitation and/ or participation restriction in an individual is considered a disability [37]. An impairment rating attempts to quantify objective pathophysiology [2] (eg, objective measurements like sensation and ROM) [24, 25]. The American Medical Association (AMA) publishes a guide to assist with the quantification of permanent impairment. Stiffness, amputation, and loss of sensation in a particular body part can be translated to whole-body impairment [38, 39]. Disability is how the impairment affects the individual and is more subjective. Questionnaires that measure disability related to the upper extremity ask patients to rate their symptoms and ability to perform specific tasks. The most commonly used upper extremity-specific disability questionnaires are the Disabilities of the Arm, Shoulder and Hand (DASH) [3, 22] and the Michigan Hand Questionnaire (MHQ) [11, 38]. Two individuals with the same impairment may experience very different levels of disability [31]. Given that the primary focus of hand therapy interventions is less disability, the relationship of impairment and disability is important to the treatment plan [5]. More disability than expected may respond to treatments based on cognitive-behavioral therapy [18].

However, there is often a lack of correspondence between impairment (objective pathophysiology [34, 35, 41] such as restriction of motion, loss of a digit, or diminished sensation) and disability (difficulty achieving ones goals). In fact, there is growing evidence that psychosocial factors (mindset and circumstances) are more important determinants of disability than objective impairment [21, 29]. Their role in predicting level of disability is not clear. Besides, there is much debate on disability construct and choosing the best outcome measure [13, 16].

There is a little evidence that used a score on impairment. To best know this relation, both impairment and disability must be evaluated in a best manner. In this study, we therefore investigate the relationship between impairment scores (quantified using the AMA guide, 6th edition), disability scores (measured using the DASH and MHQ questionnaires), and pain intensity (measured on a visual analog scale, VAS) in patients recovering from hand and upper extremity impairment after injury. Specifically, we addressed the primary null hypothesis that is their positive correlation of disability (measured by DASH and MHQ) with impairment (measured by the AMA guide). Secondary study questions addressed the effect of pain intensity and symptom of depression on predicting disability.

\section{Patients and Methods}

\section{Recruitment Procedures and Participants}

Patients recovering from hand and upper extremity injury referred by a hand surgeon after confirmation of diagnosis to the outpatient hand therapy clinic during a 6-month period (August 2014 to February 2014) were eligible, invited to fill out the questionnaires, and the impairment level was calculated after gathering all clinical evaluations. Inclusion criteria were age 18 years or older. Exclusion criteria were patients who (1) were unable to read or write; (2) had cognitive dysfunction; (3) had neurologic disease; and (4) declined participation.

All individuals gave research authorization to participate in this study. The Medical Ethics Committee of the University of Welfare Science and Rehabilitation approved the study protocol. Five hand therapists gathered the clinical data.

There were 77 men and 30 women with an average age of 34 years (range, 18-69 years). The mean time from injury was 13 months (range, 2-73 months), and the most common diagnosis was fracture, although nerve, tendon, and combined injuries all were common in this population (Table 1). 
Table 1. Frequency of categorical variables

\begin{tabular}{llc}
\hline Variables & & Number $(\%)$ \\
\hline Injured hand & Right & $37(68)$ \\
& Left & $34(32)$ \\
Dominant hand & Right & $99(92)$ \\
& Left & $8(7)$ \\
Sex & Men & $77(72)$ \\
\multirow{5}{*}{ Injury } & Women & $30(28)$ \\
& Fracture & $29(27)$ \\
& Nerve and tendon & $20(19)$ \\
& Nerve & $25(23)$ \\
& Tendon & $26(24)$ \\
& Burn & $1(1)$ \\
& Complex regional pain syndrome & $4(4)$ \\
& Amputation & $2(2)$ \\
\hline
\end{tabular}

Measures

\section{AMA Physical Impairment Rating}

The AMA Impairment Guidelines, $6^{\text {th }}$ edition, were used to quantify the percentage of upper extremity impairment based on tables and formulas using the loss of sensation (two-point discrimination), loss of motion at each joint (goniometer), and loss of strength [17].

\section{DASH Questionnaire}

The DASH questionnaire is a 30-item self-reported questionnaire to assess upper extremity symptoms and disability. Good reliability and validity have been reported. Each item is ranked on a 5-point Likert scale ranging from "no difficulty" to "unable." A composite score is calculated from the completed responses, and the score cannot be calculated if more than three items are missing. The score is scaled between 0 (no symptoms or disability) and 100 (maximum symptoms and disability) [23].

\section{MHQ Questionnaire}

The MHQ is a hand-specific outcomes questionnaire that has 57 items in six domains: (1) overall hand function; (2) activities of daily living; (3) pain; (4) work performance; (5) aesthetics; and (6) patient satisfaction. There is also a demographic section asking questions about gender, ethnic background, work status, and income. Each item is scored using a scale of 1 to 5. Each domain gets scores ranging from 0 to 100 with 0 being the worst and 100 being the best-accepted result, except the pain domain. For pain, a higher score indicates more pain. All domains except work performance and pain assess each hand separately and are scored according to the affected hand [9, 10, 18].

\section{Visual Analog Scale Pain Score}

The VAS pain score is marked on a line between 0 (no pain) and $10 \mathrm{~cm}$ (unbearable pain). Participants point to the position on the line between the faces to indicate how much pain they are currently feeling [30].

\section{Beck Depression Inventory}

The Beck Depression Inventory (BDI) consists of 21 items that assess both cognitive/affective and neurovegetative symptoms of depression in the previous week. Scoring is between 0 and 63. A score higher than 29 is considered to be indicative of major depression in chronic pain populations [1] $(0-9=$ minimal depression; $10-18=$ mild depression; 19-29 = moderate depression; $30-63=$ severe depression).

\section{Demographic Questionnaire}

A demographic questionnaire collected information on: (1) the disease (diagnosis, cause of injury, and time since injury); and (2) the patient (age, gender, dominant hand involved, work, education, marital status, laterality, kind of job (manual labor or not), employment, and current job status).

\section{Study Procedures}

Informed consent was obtained from all participating patients at their first visit. Data were collected on the day of the patient's initial visit by a team of occupational therapists experienced in hand rehabilitation and use of the AMA guide for impairment rating. The DASH, MHQ, Beck Inventory, and demographics questionnaires were completed by the patients and the intensity of pain was evaluated using a $10-\mathrm{cm}$ VAS.

\section{Statistical Analysis}

A power analysis indicated that a sample size of 100 patients would provide $80 \%$ statistical power (beta 0.20 , alpha 0.05 ) to detect a small correlation ( $\mathrm{r}=0.03$ or greater) of the DASH score with impairment rated using the AMA guides. 
Table 2. Descriptive statistics for continuous variables

\begin{tabular}{lccc}
\hline Variables & Mean & SD & Observed range \\
\hline Beck & 15 & 10.8 & $0-39$ \\
DASH & 57 & 26.3 & $0-100$ \\
AMA impairment rating & 8 & 14.1 & $0-95$ \\
MHQ & 52 & 15.1 & $12-92$ \\
Time passed from surgery (months) & 12 & 26 & $2-73$ \\
Pain (VAS) & 4 & 2.7 & $0-10$ \\
Age (years) & 3 & 12.4 & $18-69$
\end{tabular}

DASH $=$ Disabilities of the Arm, Shoulder and Hand; AMA = American Medical Association; MHQ = Michigan Hand Questionnaire; VAS $=$ visual analog scale.

The dependent (or response) variables were the DASH, the MHQ, and pain intensity. Independent (or explanatory) variables were impairment score, age, sex, diagnosis, time from surgery, and symptoms of depression.

Bivariate analyses were performed to measure the associations between response and explanatory variables. An independent-samples t-test was conducted to look for differences in continuous variables according to dichotomous distinctions. Analysis of variance (ANOVA) was used to look for differences in continuous variables for categorical variables (eg, diagnosis). Correlation of continuous response variables (eg, DASH, impairment) with continuous explanatory variables (pain, BDI, and age time passed from surgery) was analyzed using Pearson correlation. Correlation was categorized as small $(\mathrm{r}=0.10-0.29)$, intermediate $(\mathrm{r}=0.30-0.49)$, or large $(\mathrm{r}=0.50-1.00)$ [41] (Table 2).

For each response variable, a multiple linear regression model was performed to address any confounding between the explanatory variables. Variables with $\mathrm{p}<0.10$ in bivariate analysis were entered into the model. Categorical variables with more than two categories (ie, diagnosis) were analyzed by creating dummy dichotomous variables for each category.

Differences in impairment by diagnosis were tested using ANOVA with Bonferroni-adjusted post hoc tests.

\section{Results}

Disability as measured by the DASH had intermediate correlation with AMA impairment $(\mathrm{r}=0.38$, beta $=0.36$, $\mathrm{p}=0.000$ ) (Fig. 1). After controlling for relevant confounding variables, higher DASH scores were modestly correlated with AMA impairment ratings and gender $(\mathrm{r}=0.24$, beta $=0.21, \mathrm{p}<0.05)$. They accounted for $22 \%$ of the variability in DASH scores.

Disability as measured by the MHQ had a small correlation with impairment $(\mathrm{r}=-0.24$, beta $=-0.23$, $\mathrm{p}<0.05)$ and age $(\mathrm{r}=-0.20$, beta $=-0.23, \mathrm{p}<0.05)$.
After controlling for likely confounder variables, age and impairment level accounted for $23 \%$ changes in MHQ score.

Pain intensity measured by VAS did not correlate with impairment in multivariate analysis. However, pain intensity was found to correlate with the time since surgery $(\mathrm{r}=-0.33$, beta $=-0.22, \mathrm{p}<0.01)$ and symptoms of depression $(B D I)(r=0.32$, beta $=0.30, p<0.01)$. Additionally, they accounted for $18 \%$ of the variance in pain intensity.

There was also a difference in pain intensity by diagnostic group: patients with nerve injuries had substantially less pain than the other groups. Followup univariate ANOVA showed that significant differences existed between different diagnoses for the impairment score $(\mathrm{F}=3.72, \mathrm{p}<0.001)$ and severity of pain $(\mathrm{F}=2.33, \mathrm{p}<0.001)$. Bonferroni-adjusted post hoc tests showed that the patients with tendon injuries had significantly lower scores on the impairment (mean, $3.23 ; \mathrm{SD}, 6.3 ; \mathrm{p}=0.01)$ than did the patients with the nerve injury (mean, 15.1; SD, 24.4; $\mathrm{p}=0.02$ ) and the patients with amputation, burn injures, or complex regional pain syndrome who had significant upper score in impairment (mean, 19.3; SD, 13.5, $\mathrm{p}=0.05$ ). Also, the patients with amputation, those who were burn-injured, or had CRPS had significant upper scores in the severity of pain (mean, 7.8; $\mathrm{p}=0.02)$.

\section{Discussion}

Studies addressing the relationship between impairment and disability report inconsistent results [27]. Because disability can be consequence of impairment, it may be considered to have a relation with severity of the impairment. However, disability is being measured subjectively with a self-reported questionnaire and mostly is dependent on patients' intuition. Different questionnaires capture different parts of disability (activity limitation, participation restriction, or both), so knowing the factors that can change the disability level can help us in planning the interventions and also lessen disability.

We investigated the relation between impairment and disability in patients with hand and upper extremity injuries. Specifically we addressed the correlation of disability (scored by DASH and MHQ) and pain intensity with impairment (scored by AMA guide $6^{\text {th }}$ edition). We found that impairment had a small to intermediate correlation with disability based on the questionnaire used to evaluate disability.

This study has limitations. Some patients may have tired of the long assessment with three questionnaires as well as the thorough examination. Most of our patients were literate men with heavy manual work with an average 


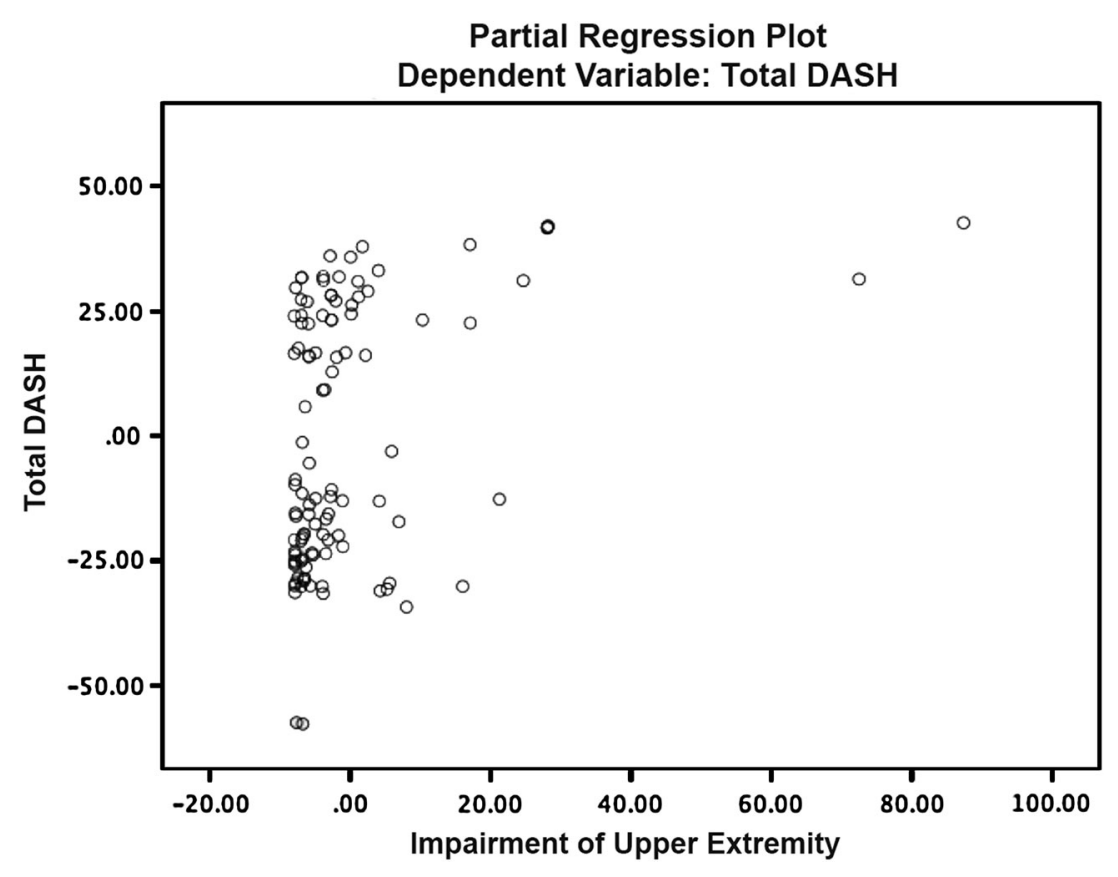

Fig. 1 The figure shows the DASH score as a function of impairment of the upper extremity.

13 months (range, 2-73 months) after their surgery. There was a wide range in time between injury and evaluation. The relationship between impairment and disability may be stronger closer to the injury and different based on patient gender, job, and societal status, so long after the injury, patients have had time to adapt. Besides, the AMA guide is used to evaluate permanent impairment and we had some patients who just passed the chronic phase of their treatment ( 2 months). Impairment rating may be prone to measurement error. Some of the evaluations such as manual muscle testing have not good interrater reliability.

Perhaps the BDI was not the best measure of symptoms of depression in patients with hand injuries in part because there is doubt about its responsiveness and it is prone to ceiling effects $[19,20,32]$.

Our finding of an intermediate correlation of AMA impairment rating with DASH is partly in agreement with the findings of prior studies. A study of patients with hand fractures found a small correlation between AMA impairment ratings and DASH scores 6 months after hand trauma (correlation coefficients, 0.3-0.4). Chapman et al. [5] found a moderate correlation $(r=0.50)$ between impairment and disability at discharge and a moderately high correlation $(\mathrm{r}=0.74)$ at followup in the early part of recovery after burn injury and a large correlation 4 months after burn injuries. In contrast, van Oosterom et al. [40] found no correlation between AMA impairment rating and DASH an average of 7.5 years after phalangeal fracture.

To our knowledge the relationship between AMA impairment ratings and disability measured with the MHQ was previously untested. We found a small correlation between MHQ and impairment was not similar to that for the DASH. These two outcome measure are routinely used for evaluating disability, but because they are not captured, all the domains of disability constructs based on ICF (International Classification of Function and Diseases) $[6,15]$ are the same; they may present a different view of disability.

DASH questions are mostly about activity limitation (such as turning a key, washing your back), but MHQ mostly addressed participation restriction (pain, satisfaction, problems in doing activities) $[7,16]$.

Based on ICF, it can be predictable that severity of impairment correlates with activity limitation, but participation is restricted mostly under the influence of personal and environmental factors.

The moderate correlation between pain intensity and symptoms of depression is consistent with prior work [4, 28]. In a longitudinal study on 500 patients with persistent pain, pain and depression had strong and similar effects on one another over a 12-month period [26]. There is substantial evidence that the substantial variation in symptom intensity and magnitude of disability for a given pathophysiology is best explained by psychological and sociological factors. A variety of factors have been postulated to explain the pain-depression relationship. Maladaptive coping skills (praying and hoping), low selfefficacy, and other coping strategies (diverting attention, ignoring pain sensations, increasing activity level) may play important mediating roles $[8,12]$. 
Inconsistent with prior research that consistently finds symptoms of depression account for a substantial part of the variance in DASH scores $[14,33,36]$, we found that severity of depression is not a predictor of disability.

The lack of a strong correlation between AMA impairment ratings and DASH and MHQ scores confirms that impairment does not correspond precisely with disability. It can be interpreted that the perceived disability and the patient expectations are not the same as our clinical evaluations. Having a self-reported questionnaire can help to know the priority of the patients to improve the treatment plan. Decreasing impairment can be helpful in decreasing disability but not fully. Knowing the factors that can affect this relation can help us to use them in the therapeutic strategy. The correlation of pain intensity with symptoms of depression reminds us that we need to treat the whole person when the hand is injured. Despite some limitations, these results point to potentially fruitful areas for further research. For example, it would be interesting to use a longitudinal design, sampling patients when they first injure themselves and follow them through the whole recovery process, measuring all potential factors that can change the disability level (coping strategies and psychological distress). Then we could create targeted interventions for other treatment options (cognitive and emotional support of hand-injured patients) and study whether they decrease symptoms and disability.

Acknowledgments We thank Dr David Ring, Associate Professor of Orthopedic Surgery, Harvard Medical School, for his kind guidance in all parts of the study.

\section{References}

1. Axelrod DA, Geisser ME, Roth RS, Greenfield LJ. Outcomes after surgery for thoracic outlet syndrome. J Vasc Surg. 2001;33:1220-1225.

2. Bindra R, Dias J, Heras-Palau C, Amadio P, Chung K, Burke F. Assessing outcome after hand surgery: the current state. J Hand Surg [Br]. 2003;28:289-294.

3. Bot S, Terwee C, Van der Windt D, Bouter L, Dekker J, De Vet H. Clinimetric evaluation of shoulder disability questionnaires: a systematic review of the literature. Ann Rheum Dis. 2004;63:335341.

4. Calderon SAL, Zurakowski D, Davis JS, Ring D. Quantitative adjustment of the influence of depression on the Disabilities of the Arm, Shoulder, and Hand (DASH) questionnaire. Hand. 2010;5:49-55.

5. Chapman TT, Richard RL, Hedman TL, Renz EM, Wolf SE, Holcomb JB. Combat casualty hand burns: evaluating impairment and disability during recovery. J Hand Ther. 2008;21: 150-159.

6. Cieza A, Ewert T, Ustun TB, Chatterji S, Kostanjsek N, Stucki G. Development of ICF Core sets for patients with chronic conditions. J Rehabil Med. 2004;4:9-11.

7. Coenen M, Kus S, Rudolf K-D, Müller G, Berno S, Dereskewitz C, MacDermid J. Do patient-reported outcome measures capture functioning aspects and environmental factors important to individuals with injuries or disorders of the hand? $J$ Hand Ther. 2013;26:332-342.

8. Covic T, Adamson B, Spencer D, Howe G. A biopsychosocial model of pain and depression in rheumatoid arthritis: a 12-month longitudinal study. Rheumatology. 2003;42:1287-1294.

9. Chung KC, Burns PB, Sears ED. Outcomes Research in Hand Surgery: where have we been and where should we go? J Hand Surg [Am]. 2006;31:1373-1380.

10. Chung KC, Hamill JB, Walters MR, Hayward RA. The Michigan Hand Outcomes Questionnaire (MHQ): assessment of responsiveness to clinical change. Ann Plast Surg. 1999;42:619.

11. Chung KC, Pillsbury MS, Walters MR, Hayward RA. Reliability and validity testing of the Michigan Hand Outcomes Questionnaire. J Hand Surg. 1998;23:575.

12. Dersh J, Polatin PB, Gatchel RJ. Chronic pain and psychopathology: research findings and theoretical considerations. Psychosom Med. 2002;64:773-786.

13. Dixon D, Johnston M, McQueen M. The Disabilities of the Arm, Shoulder and Hand Questionnaire (DASH) can measure the impairment, activity limitations and participation restriction constructs from the International Classification of Functioning, Disability and Health (ICF). BMC Musculoskelet Disord. 2008; 9:114.

14. Doornberg JN, Ring D, Fabian LM, Malhotra L, Zurakowski D, Jupiter JB. Pain dominates measurements of elbow function and health status. J Bone Joint Surg Am. 2005;87:1725-1731.

15. Drummond AS, Sampaio RF, Mancini MC, Kirkwood RN, Stamm TA. Linking the Disabilities of Arm, Shoulder, and Hand to the International Classification of Functioning, Disability, and Health. $J$ Hand Ther. 2007;20:336-344.

16. Farzad M, Layeghi F, Asgari A, Hosseini SA, Rassafiani M. Evaluation of nondiseased specified outcome measures in hand injuries to assess activity and participation based on ICF content. $J$ Hand Microsurg. 2014;6:27-34.

17. Forst L, Friedman L, Chukwu A. Reliability of the AMA guides to the evaluation of permanent impairment. J Occup Environ Med. 2010;52:1201-1203.

18. Fowler D, French P, Hodgekins J, Lower R, Turner R, Burton S, Wilson J. CBT to address and prevent social disability in early and emerging psychosis. CBT for Schizophrenia: Evidence-Based Interventions and Future Directions. 2013:143-167.

19. Furlanetto LM, Mendlowicz MV, Romildo Bueno J. The validity of the Beck Depression Inventory-Short Form as a screening and diagnostic instrument for moderate and severe depression in medical inpatients. $J$ Affect Disord. 2005;86:87-91.

20. Golden J, Conroy RM, O'Dwyer AM. Reliability and validity of the Hospital Anxiety and Depression Scale and the Beck Depression Inventory (Full and FastScreen scales) in detecting depression in persons with hepatitis C. $J$ Affect Disord. 2007;100:265-269.

21. Hill S, Dziedzic KS, Ong BN. The functional and psychological impact of hand osteoarthritis. Chronic Illn. 2010;6:101-110.

22. Hudak PL, Amadio PC, Bombardier C, Beaton D, Cole D, Davis A, Hawker G, Katz JN, Makela M, Marx RG. Development of an upper extremity outcome measure: the DASH (Disabilities of the Arm, Shoulder, and Head). Am J Ind Med. 1996;29:602-608.

23. Hudak PL, McKeever PD, Wright JG. Understanding the meaning of satisfaction with treatment outcome. J Bone Joint Surg Am. 2004;42:718-725.

24. Janda DH, Geiringer SR, Hankin FM, Barry DT. Objective evaluation of grip strength. J Occup Environ Med. 1987;29:569571.

25. Jebsen RH, Taylor N, Trieschmann R, Trotter M, Howard L. An objective and standardized test of hand function. Arch Phys Med Rehabil. 1969;50:311. 
26. Kroenke K, Wu J, Bair MJ, Krebs EE, Damush TM, Tu W. Reciprocal relationship between pain and depression: a 12month longitudinal analysis in primary care. $J$ Pain. 2011;12:964-973.

27. Lindenhovius AL, Buijze GA, Kloen P, Ring DC. Correspondence between perceived disability and objective physical impairment after elbow trauma. J Bone Joint Surg Am. 2008;90:2090-2097.

28. MacDermid JC, Donner A, Richards RS, Roth JH. Patient versus injury factors as predictors of pain and disability six months after a distal radius fracture. J Clin Epidemiol. 2002;5:849-854.

29. Marinus J, Moseley GL, Birklein F, Baron R, Maihfner C, Kingery WS, van Hilten JJ. Clinical features and pathophysiology of complex regional pain syndrome. Lancet Neurol. 2011;10: 637-648.

30. Michele Koleck A, Mazaux J-M, Rascle N, Bruchon-Schweitzer M. Psycho-social factors and coping strategies as predictors of chronic evolution and quality of life in patients with low back pain: a prospective study. Eur J Pain. 2005;10:1-11.

31. Mink Van Der Molen A, Ettema A, Hovius S. Outcome of hand trauma: the hand injury severity scoring system (HISS) and subsequent impairment and disability. J Hand Surg [Br]. 2003;28:295-299.

32. Navines R, Castellvi P, Moreno-Espana J, Gimenez D, Udina M, Canizares S, Diez-Quevedo C, Valds M, Sols R, Martn-Santos R. Depressive and anxiety disorders in chronic hepatitis $\mathrm{C}$ patients: Reliability and validity of the Patient Health Questionnaire. $J$ Affect Disord. 2012;138:343-351.
33. Niekel MC, Lindenhovius AL, Watson JB, Vranceanu A-M, Ring D. Correlation of DASH and QuickDASH with measures of psychological distress. J Hand Surg. 2009;34:1499-1505.

34. Nieto R, Raichle KA, Jensen MP, Miro J. Changes in pain-related beliefs, coping, and catastrophizing predict changes in pain intensity, pain interference, and psychological functioning in individuals with myotonic muscular dystrophy and facioscapulohumeral dystrophy. Clin J Pain. 2012;28:47.

35. Ramond A, Bouton C, Richard I, Roquelaure Y, Baufreton C, Legrand E, Huez J-FB. Psychosocial risk factors for chronic low back pain in primary care-a systematic review. Fam Pract. 2011:28:12-21.

36. Robinson JP, Turk DC, Loeser JD., Pain, impairment, and disability in the AMA guides. J Law Med Ethics. 2004;32:315-326.

37. Rondinelli RD, Genovese E, Brigham CR. Guides to the Evaluation of Permanent Impairment. Chicago, IL, USA: American Medical Association; 2008.

38. Shauver MJ, Chung KC. The minimal clinically important difference of the Michigan hand outcomes questionnaire. J Hand Surg. 2009;34:509-514.

39. Spieler EA, Barth PS, Burton JF Jr, Himmelstein J, Rudolph L. Recommendations to guide revision of the Guides to the Evaluation of Permanent Impairment. JAMA. 2000;283:519-523.

40. van Oosterom FJ, Ettema AM, Mulder PG, Hovius SE. Impairment and disability after severe hand injuries with multiple phalangeal fractures. J Hand Surg. 2007;32:91-95.

41. Vranceanu A-M, Jupiter JB, Mudgal CS, Ring D. Predictors of pain intensity and disability after minor hand surgery. $J$ Hand Surg. 2010;35:956-960. 